\title{
Current use of medical expulsive therapy among endourologists
}

Donald Charles Fedrigon, MD; Rajat Jain, MD; Sri Sivalingam, MD

Cleveland Clinic- Glickman Urological \& Kidney Institute, Cleveland, OH, United States

Cite as: Can Urol Assoc J 2018 May 14; Epub ahead of print. http://dx.doi.org/10.5489/cuaj.4978

Published online May 14, 2018

\begin{abstract}
Introduction: We aimed to characterize current practice patterns among endourologists on medical expulsive therapy (MET) for treatment of ureteral calculi.

Methods: An online survey was administered to Endourological Society members.

Respondents' MET usage, index case management, and awareness of recent guidelines and literature were compared based on international status, practice setting, interval since training, and endourological fellowship training.

Results: Of the 237 complete responses, $65 \%$ were international, $61 \%$ were academic, $66 \%$ had $>10$ years in practice, and $71 \%$ were endourology fellowship-trained. MET was used by $88 \%$, with no differences between international, academic, practice length, and fellowshiptrained groups. MET was used more frequently for $<8 \mathrm{~mm}$ and distal stones and more U.S.based respondents reported use for proximal/midureteral stones ( $68 \%$ vs $43 \%$; $p<0.001$ ). For the index patient, $70 \%$ preferred MET as the initial approach and respondents $<10$ years from training were more likely to choose MET ( $82 \%$ vs. $64 \%$; $\mathrm{p}=0.006$ ). While $82 \%$ of respondents were aware of the SUSPEND trial, 70\% reported that it had not altered their use of MET. Current American Urological Association (AUA) guideline awareness was 90\%. Mean MET prescription length was $19.9 \pm 10.3$ days, and was statistically significantly longer for respondents who were U.S.-based, academic and $<10$ years from training. Conclusions: MET is the preferred approach for patients with ureteral calculi $<10 \mathrm{~mm}$ among endourologists despite conflicting data in the literature. While current AUA practice guidelines are followed by the majority of respondents, our survey suggests MET is being used more liberally than the guideline criteria, specifically in proximal and midureteral stones.
\end{abstract}




\section{Introduction}

Medical expulsive therapy (MET) is a frequently utilized approach in the management of ureteral calculi. Although it is a recommended initial option per the current AUA guidelines, recent studies have challenged this paradigm. ${ }^{1}$ The Pickard et al. (SUSPEND) and Furyk et al. trials were two large multicenter, randomized controlled trials published in 2015 that found spontaneous passage rate of ureteral stones to be similar for patients prescribed MET compared to placebo. ${ }^{2,3}$

Current American Urological Association (AUA) guidelines published in May 2016 recommend MET only for patients with distal ureteral stones $\leq 10 \mathrm{~mm}$ while the European Association of Urology (EAU) guidelines recommend use for all ureteral stones. ${ }^{1,4}$ Furyk et al. also found that MET increased the likelihood of spontaneous stone passage in a subset of larger stones $5-10 \mathrm{~mm}$ in size $(\mathrm{p}=0.03){ }^{3}$ A recent systematic meta-analysis of MET studies by Hollingsworth et al. included both SUSPEND and Furyk data and concluded that MET increased the likelihood of stone passage for stones $\geq 5 \mathrm{~mm}$, regardless of location. ${ }^{5}$ The conflicting data in the above studies and guidelines has generated some doubt about the efficacy of MET.

Given the context of recent challenges, we sought to characterize current practice patterns and perspectives on MET for the treatment of ureteral calculi among members of the endourological society. A better understanding of current practice patterns, knowledge of the literature and attitudes with regards to MET among practicing urologists could help determine the need for further studies and improve evidence based education on the initial management of ureteral calculi.

\section{Methods}

An online survey was designed and administered to members of the Endourological Society in August and September of 2016 via the REDCap platform hosted at the Cleveland Clinic Foundation. ${ }^{6}$ Study data was collected and managed using REDCap's electronic data capture tools. Consisting of 22 questions, the survey included an index case that served as the basis for a series of management options. The index case was described as a patient "presenting with ureteral calculi $\leq 10 \mathrm{~mm}$, adequately controlled pain, and without fever" (Full survey in supplemental data). Additionally, we captured other metrics including demographics, international status, type of practice, interval since training completion, fellowship training in endourology, as well as individual perspectives and knowledge on MET.

Using email addresses in the Endourological Society's member database, the survey was sent twice to 2,815 recipients spaced two weeks apart. Responses were recorded and anonymized automatically through the REDCap system and surveys were eliminated from statistical analysis if $\leq 14$ questions were unanswered (i.e. the equivalent of stopping after the first page). MET usage and index case management were evaluated based on respondents' international status, practice setting, interval since training completion, and fellowship training. Statistical analysis was performed via Pearson chi-square, Fisher's 
exact, cross-tabulation, and Student's t-tests using IBM SPSS Statistics for Windows, version 24 (IBM Corp., Armonk, N.Y., USA).

\section{Results}

Two hundred and thirty-seven completed responses were received with 285 surveys being opened but not completed beyond the first page of the survey, giving a completion rate of $83 \%$. Of the completed responses $65 \%$ were international, $61 \%$ were academic urologists, $66 \%$ had $>10$ years in practice, and $71 \%$ were fellowship-trained in endourology (Full demographic data supplemental data). The majority of respondents (88\%) reported using MET for patients with ureteral calculi with no significant differences between the international, academic, practice length, and fellowship trained groups (Table 1). For the index patient MET was the preferred initial approach for $70 \%$ of respondents, followed by observation in 14\%, and surgical options (URS, SWL, and stent placement) in $16 \%$. Respondents within 10 years of training were significantly more likely to choose MET (82\% vs $64 \%$, $\mathrm{p}=0.006$, Table 1 ).

Overall, 82\% percent of respondents reported being aware of the results of the SUSPEND trial, with higher awareness among urologists from the US (89\% vs 78\%, $\mathrm{p}=0.043$, Table 1 ), those with endourology fellowship training ( $86 \%$ vs $75 \%, \mathrm{p}=0.038$ ), and those in academic practice ( $89 \%$ vs $72 \%, \mathrm{p}=0.001$ ). Although awareness was high, $70 \%$ of respondents reported that the results had not altered their use of MET. Additionally, $90 \%$ reported being aware of the current AUA guidelines on the surgical management of stones with no significant variation based on duration of practice or academic practice setting (Table 1).

Mean MET prescription length was $19.9 \pm 10.3$ days for all respondents and 37\% prescribed MET for $\geq 28$ days, the prescription length used in the SUSPEND and Furyk et al. trials. ${ }^{2,3}$ MET prescriptions were significantly longer for respondents who were US-based (22.9 vs 18.1 days, $\mathrm{p}=0.001$, Table 1 ), in academic settings (22.3 vs 16.1 days, $\mathrm{p}<0.001$ ), and within 10 years of training (23.9 vs 17.7 days, $\mathrm{p}<0.001$ ).

Respondents utilized MET more often for distal stones as compared to mid-ureter or proximal stones ( $98 \%$ vs $59 \%$ vs $44 \%$ respectively, Table 2 ). For stones sized $5-8 \mathrm{~mm}$, 8 $10 \mathrm{~mm}$, and $>10 \mathrm{~mm}, 76 \%, 33 \%$ and $8 \%$ of respondents reported using MET, respectively (Table 2). US-based respondents were more likely to use MET for proximal and midureteral stones (68\% vs $43 \%, p<0.001$, Table 3 ) as well as for stones $>10 \mathrm{~mm}(13 \%$ vs $4 \%$, $\mathrm{p}=0.009$ ). Twenty-nine percent of respondents reported that they would prescribe MET to pregnant patients with ureteral calculi and $18 \%$ reported that they were unsure or would defer to an obstetrician with no significant variations based on academic practice setting (Table 4).

US-based respondents within 10 years of training were more likely to agree that additional education of emergency department physicians on MET is necessary (94\% vs $76 \%, \mathrm{p}=0.033$ ). Respondents in academic settings were significantly less likely to report an ED to clinic follow-up time of less than 1 week ( $58 \%$ vs $81 \%$, $p<0.001$, Table 4 ). 


\section{Discussion}

The criteria for the initiation and use of MET have been the subject of debate in the urologic community, given the discordance in data from several studies. We evaluated real world utilization of MET as well as the awareness and impact of relevant literature and guidelines amongst endourologists.

Our results suggest that the majority of endourologists prefer MET as an initial approach to managing ureteral calculi. This trend is consistent across duration, location, and type of practice as well as endourological fellowship training. Interestingly, our rate of MET usage was slightly lower than a survey by Lloyd et al. (88.4\% vs $99.6 \%)$ which collected data ending in June of 2015, just prior to the publication of the SUSPEND trial. ${ }^{7}$ This could be attributed to a decline in MET usage based on data refuting its efficacy, or perhaps this reflects an overall higher utilization in a broader survey target group which included both endourologists and general urologists. Another finding in our survey is that few endourologists (29\%) report use of MET in pregnant patients. Lloyd et al. showed a similar trend and further elucidated that concern of legal risk and patient safety contributed significantly to physician nonuse of MET during pregnancy. ${ }^{7}$ Nonetheless, recent evidence has emerged regarding the safety of using tamsulosin in pregnant females, while the FDA continues to class tamsulosin as category B, indicating no evidence of fetal harm shown in animal studies. ${ }^{8}$

Respondents with specific endourology fellowship training did not prescribe MET more often than their non-fellowship trained counterparts, but were more likely to report being aware of the current literature. The current AUA guidelines only recommend MET for patients with distal stones $<10 \mathrm{~mm}$ in size and the EAU recommends MET for all ureteral stones. ${ }^{1,4}$ However, it is foreseeable that future guidelines will continue to evolve to factor in the results from the SUSPEND trial and other future large scale RCTs. ${ }^{9}$ Of our US respondents, $13 \%$ used MET for stones $>10 \mathrm{~mm}$ in size and $68 \%$ used MET for stones in the proximal or mid ureter. This reflects a deviation from the AUA guidelines, and is a significantly higher rate than international respondents. Adherence to the AUA guidelines as measured by MET usage in stones $>10 \mathrm{~mm}$ or in the proximal/mid ureter, was not significantly impacted by either endourology fellowship training or interval from training (Table 3). It is important to note that at the time the survey was administered, the new AUA guidelines had been in place for only 4 months. ${ }^{1}$ It is possible that some of the reported use of MET beyond the scope of the AUA guidelines is due to physicians not being aware of the new guidelines or are following the EAU guidelines, but these are not conclusions we can draw from our study design.

A recent patient questionnaire by Bell et al. found that $49 \%$ of patients would try tamsulosin after being given a summary of the conflicting data for MET and $25 \%$ were unsure; $71 \%$ preferred trying medical therapy before pursuing surgical options. ${ }^{10}$ It appears that both patient and physician preferences do not currently reflect recent prospective 
evidence, as evidenced by our finding that $70 \%$ of endourologists have not changed their usage of MET in response to the recent trials. In addition, with nearly half of patients willing to try MET despite recent evidence based on the Bell et al. results and $85 \%$ of our respondents recommending more research on MET, it will be important to disseminate future literature findings to both patients and physicians to aid in clinical recommendations.

There appears to be some disparity between the available evidence on MET and the current guidelines. Additionally, our data suggests expanded use of MET beyond the criteria set by the guidelines. Both of these trends indicate that practice patterns and patient care could benefit from clear guidelines backed by more conclusive literature on the use and efficacy of MET. Better tools for the translation of both current guidelines and recent literature findings to physicians might become a future clinical priority when a consensus on the use of MET is reached.

This report highlights the current trends and preferences among endourologists regarding MET and management of ureteral stones. One limitation of our study is that the survey design limits our abilities to draw conclusions regarding underlying explanations for the observed trends. Additionally, since our sample consisted of practicing Endourological Society members, our respondent population is unique in their expertise with endourology and stone disease, which may limit our ability to generalize the observed trends to the wider community of practicing urologists.

The completion rate for opened surveys was $83 \%$ and a total of 237 responses were recorded from the 2,815 Endourological Society members contacted. For comparison, Lloyd et al. did not record a response rate but received 537 responses from surveys sent to mailing lists from the regional sections of the AUA as well as the Endourological Society. Considering this our response rate and total number of completed surveys seems adequate given only the Endourological Society was used for our survey and the number of opened surveys could have been impacted by inactive or outdated emails.

While the AUA or EAU guidelines do not specify length of MET, our data showed an average usage of MET for $19.9 \pm 10.3$ days, which is shorter than the duration of 28 days examined in large recent scale trials. ${ }^{2,3}$ Respondents in the US, in academic settings, and with an interval from training of less than 10 years all had significantly longer prescription lengths for MET. With regards to our index patient, the majority of respondents preferred MET as the initial approach, followed by observation and surgical intervention.

Interestingly, urologists within 10 years of training were significantly more likely to choose MET.

Respondents in academic practice settings were significantly less likely to report a clinic follow-up time after initial ED encounter of less than 1 week. Although we did not elucidate the causality of this in our survey, it is possible that less available clinic time and longer duration of prescribed MET in an academic practice necessarily pushes back followup appointments to a later time.

Of our respondent population, $82 \%$ reported aware of the controversy surrounding the SUSPEND trial results. Significantly, 70\% reported that this had not changed their practice 
regarding MET. This may be a reflection of endourologists awaiting more convincing evidence before changing established practice. It will be interesting to observe the evolution of the use of MET as more data emerges and as the guidelines are updated in the future.

A previous study at our institution estimated that half of ED patients who met criteria for MET did not receive it. ${ }^{11}$ There was a consensus among our respondents that more education of ED personnel is necessary to standardize prescription and usage of MET, suggesting that this might be a commonly encountered issue for our respondents.

Additionally, nearly $85 \%$ of respondents recommended more research on MET. In light of this, we have developed a standardized stone care protocol in conjunction with ED physicians for patients with renal colic.

\section{Conclusion}

Medical expulsive therapy continues to be the preferred initial approach for patients with ureteral calculi $<10 \mathrm{~mm}$ among endourologists despite conflicting data in the literature. While the current AUA practice guidelines are followed by the majority of respondents, it is notable that our survey suggests MET is being used more liberally than the criteria established in the guidelines, specifically in proximal and mid ureteral stones. 


\section{References}

1. Assimos D, Krambeck A, Miller NL, et al. Surgical Management of Stones: American Urological Association/Endourological Society Guideline, PART II. $J$ Urol. 2016;196(4):1161-1169. doi:10.1016/j.juro.2016.05.091.

2. Pickard R, Starr K, MacLennan G, et al. Medical expulsive therapy in adults with ureteric colic: A multicentre, randomised, placebo-controlled trial. Lancet. 2015;386(9991):341-349. doi:10.1016/S0140-6736(15)60933-3.

3. Furyk JS, Chu K, Banks C, et al. Distal Ureteric Stones and Tamsulosin: A DoubleBlind, Placebo-Controlled, Randomized, Multicenter Trial. Ann Emerg Med. 2016;67(1):86-95.e2. doi:10.1016/j.annemergmed.2015.06.001.

4. Türk C, Petřík A, Sarica K, et al. EAU Guidelines on Diagnosis and Conservative Management of Urolithiasis. Vol 69.; 2016. doi:10.1016/j.eururo.2015.07.040.

5. Hollingsworth JM, Canales BK, Rogers MAM, et al. Alpha blockers for treatment of ureteric stones: systematic review and meta-analysis. Bmj. 2016;355(6):2418-2434. doi:10.1136/bmj.i6112.

6. Harris PA, Taylor R, Thielke R, Payne J, Gonzalez N, Conde JG. Research electronic data capture (REDCap) — A metadata-driven methodology and workflow process for providing translational research informatics support. J Biomed Inform. 2009;42(2):377-381. doi:10.1016/j.jbi.2008.08.010.

7. Lloyd GL, Lim A, Hamoui N, Nakada SY, Kielb SJ. The Use of Medical Expulsive Therapy During Pregnancy: A Worldwide Perspective Among Experts. J Endourol. 2016;30(3):354-358. doi:10.1089/end.2015.0587.

8. Bailey G, Vaughan L, Rose C, Krambeck A. Perinatal Outcomes with Tamsulosin Therapy for Symptomatic Urolithiasis. J Urol. 2016;195(1):99-103. doi:10.1016/j.juro.2015.06.097.

9. Bultitude M, Smith D, Thomas K. Contemporary Management of Stone Disease: The New EAU Urolithiasis Guidelines for 2015. Eur Urol. 2016;69(3):483-484. doi:10.1016/j.eururo.2015.08.010.

10. Bell JR, Penniston KL, Best SL, Nakada SY. A survey of patient preferences regarding medical expulsive therapy following the SUSPEND trial. Can J Urol. 2017;24(June):8827-8831.

11. Loftus C, Nyame Y, Hinck B, et al. Medical Expulsive Therapy is Underused for the Management of Renal Colic in the Emergency Setting. J Urol. 2016;195(4):987-991. doi:10.1016/j.juro.2015.11.026. 


\section{Figures and Tables}

\begin{tabular}{|c|c|c|c|c|c|c|c|c|c|c|c|c|}
\hline & U.S. & International & $\mathbf{p}$ & Academic & $\begin{array}{c}\text { Non- } \\
\text { academic }\end{array}$ & $\mathbf{p}$ & $\leq 10$ years & $\begin{array}{c}>10 \\
\text { years }\end{array}$ & $\mathbf{p}$ & Fellow & Non-fellow & $\mathbf{p}$ \\
\hline $\begin{array}{l}\text { Currently prescribe } \\
\text { MET }\end{array}$ & $94 \%(76)$ & 87\% (129) & 0.115 & $90 \%$ (125) & $89 \%(80)$ & 0.802 & $91 \%(72)$ & $\begin{array}{c}89 \% \\
(133)\end{array}$ & 0.561 & $\begin{array}{l}88 \% \\
(130)\end{array}$ & $91 \%(75)$ & 0.473 \\
\hline $\begin{array}{l}\text { Preferred initial } \\
\text { approach }\end{array}$ & & & $0.507^{*}$ & & & $0.077^{*}$ & & & $0.031^{*}$ & & & $0.680 *$ \\
\hline Observation & $12 \%(10)$ & $14 \%(22)$ & & $15 \%(21)$ & $12 \%(11)$ & & $10 \%(8)$ & $15 \%(24)$ & & $15 \%(23)$ & $11 \%(9)$ & \\
\hline MET & $76 \%(64)$ & 67\% (102) & & 74\% (107) & $63 \%(59)$ & & $82 \%(66)$ & $\begin{array}{c}64 \% \\
(100) \\
\end{array}$ & & $\begin{array}{l}71 \% \\
(109) \\
\end{array}$ & $69 \%$ (57) & \\
\hline URS & $8 \%(7)$ & $10 \%(15)$ & & $6 \%(8)$ & $15 \%(14)$ & & $4 \%(3)$ & $12 \%(19)$ & & $8 \%(13)$ & $11 \%(9)$ & \\
\hline SWL & $2 \%(2)$ & $7 \%(11)$ & & $4 \%(6)$ & $8 \%(7)$ & & $3 \%(2)$ & 7\% (11) & & $5 \%(7)$ & $7 \%(6)$ & \\
\hline Stenting & $1 \%(1)$ & $2 \%(3)$ & & $1 \%(2)$ & $2 \%(2)$ & & $3 \%(2)$ & $1 \%(2)$ & & $1 \%(2)$ & $2 \%(2)$ & \\
\hline $\begin{array}{l}\text { NT placement } \\
\text { (excluded) }\end{array}$ & $0 \%(0)$ & $0 \%(0)$ & & $0 \%(0)$ & $0 \%(0)$ & & $0 \%(0)$ & $0 \%(0)$ & & $0 \%(0)$ & $0 \%(0)$ & \\
\hline $\begin{array}{l}\text { Preferred approach - } \\
\text { MET only }\end{array}$ & $67 \%(102)$ & $76 \%(64)$ & 0.126 & 74\% (107) & $63 \%(59)$ & 0.075 & $82 \%(66)$ & $\begin{array}{l}64 \% \\
(100)\end{array}$ & 0.006 & $\begin{array}{l}71 \% \\
(109) \\
\end{array}$ & $69 \%(57)$ & 0.736 \\
\hline $\begin{array}{l}\text { Reported being aware } \\
\text { of SUSPEND trial } \\
\text { controversy }\end{array}$ & $89 \%(73)$ & $78 \%(116)$ & 0.043 & $89 \%(125)$ & $72 \%(64)$ & 0.001 & $84 \%(67)$ & $\begin{array}{l}81 \% \\
(122) \\
\end{array}$ & 0.648 & $\begin{array}{r}86 \% \\
(129) \\
\end{array}$ & $75 \%(60)$ & 0.038 \\
\hline $\begin{array}{l}\text { Aware of the AUA } \\
\text { guidelines on the } \\
\text { surgical management of } \\
\text { stones }\end{array}$ & -- & -- & & 91\% (128) & $90 \%(81)$ & 0.844 & $89 \%(71)$ & $\begin{array}{l}91 \% \\
(138)\end{array}$ & 0.515 & -- & -- & \\
\hline $\begin{array}{l}\text { Mean length of MET } \\
\text { prescription in days } \\
\text { (SD) }\end{array}$ & 22.9 (10.7) & $18.1(9.7)$ & 0.001 & $22.3(10.5)$ & $16.1(8.7)$ & $<0.001$ & $\begin{array}{c}23.9 \\
(10.7)\end{array}$ & $17.7(9.4)$ & $<0.001$ & $\begin{array}{c}20.7 \\
(10.9)\end{array}$ & $18.4(9.1)$ & 0.118 \\
\hline
\end{tabular}

Data represents responses to survey questions on MET prescribing practices accompanied by analysis based on respondent demographics. ${ }^{*}$ Fisher's exact test instead of Chi-square due to small sample sizes. MET: medical expulsive therapy; SD: standard deviation. 


\begin{tabular}{|l|l|}
\hline \multicolumn{2}{|l|}{ Table 2. MET usage by stone size and location } \\
\hline Variable & $\begin{array}{l}\text { Percentage of } \\
\text { respondents (n) }\end{array}$ \\
\hline Location & \\
\hline Proximal & $44 \%(91)$ \\
\hline Mid & $59 \%(121)$ \\
\hline Distal & $98 \%(200)$ \\
\hline Size & \\
\hline$<5 \mathrm{~mm}$ & $74 \%(152)$ \\
\hline $5-8 \mathrm{~mm}$ & $76 \%(156)$ \\
\hline $8-10 \mathrm{~mm}$ & $33 \%(67)$ \\
\hline$>10 \mathrm{~mm}$ & $8 \%(17)$ \\
\hline
\end{tabular}

Data represents the percentage of respondents reporting MET usage based on stone size and location in ureter. MET: medical expulsive therapy;

\begin{tabular}{|c|c|c|c|c|c|c|c|c|c|}
\hline & U.S. & International & $\mathbf{p}$ & Fellow & Non-fellow & $\mathbf{p}$ & $\leq 10$ years & $>10$ years & $\mathbf{p}$ \\
\hline Use MET for proximal or mid stones & $68 \%(57)$ & $43 \%(65)$ & $<0.001$ & $50 \%(77)$ & $54 \%(45)$ & 0.535 & $58 \%(47)$ & $48 \%(75)$ & 0.146 \\
\hline Use MET for distal stones & $89 \%(75)$ & $82 \%(125)$ & 0.124 & $83 \%(127)$ & $88 \%(73)$ & 0.267 & $88 \%(71)$ & $83 \%(129)$ & 0.318 \\
\hline Use MET for stones $<10 \mathrm{~mm}$ & $88 \%(74)$ & $84 \%(128)$ & 0.357 & $83 \%(127)$ & $90 \%(75)$ & 0.102 & $88 \%(71)$ & $84 \%(131)$ & 0.449 \\
\hline Use MET for stones $>10 \mathrm{~mm}$ & $13 \%(11)$ & $4 \%(6)$ & 0.009 & $8 \%(13)$ & $5 \%(4)$ & 0.303 & $11 \%(9)$ & $5 \%(8)$ & 0.090 \\
\hline
\end{tabular}

Data represents answer choice percentages and comparative data analysis based on respondent demographics. MET: medical expulsive therapy. 


\begin{tabular}{|c|c|c|c|}
\hline & Academic & $\begin{array}{c}\text { Non- } \\
\text { academic }\end{array}$ & $\mathbf{p}$ \\
\hline ED to clinic followup time $<1$ week & $58 \%(83)$ & $81 \%(75)$ & $<0.001$ \\
\hline $\begin{array}{l}\text { Recommends more research on MET is } \\
\text { warranted (\%) }\end{array}$ & $83 \%(117)$ & $88 \%(79)$ & 0.321 \\
\hline $\begin{array}{l}\text { Recommends more education of ED } \\
\text { personnel on MET is necessary (\%) }\end{array}$ & $92 \%(129)$ & $86 \%(77)$ & 0.157 \\
\hline Recommends MET for pregnant patients & & & 0.644 \\
\hline Yes & $32 \%(45)$ & $26 \%(24)$ & \\
\hline No & $51 \%(73)$ & $55 \%(51)$ & \\
\hline Defer to obstetrics & $18 \%(25)$ & $19 \%(18)$ & \\
\hline
\end{tabular}

Displays academic and non-academic responses for various MET related questions and analysis based on practice type. ED: emergency department; MET: medical expulsive therapy. 


\begin{tabular}{|c|c|}
\hline \multicolumn{2}{|l|}{ Supplementary Table 1. Full survey text } \\
\hline \multicolumn{2}{|l|}{ Section 1: Demographic and education information } \\
\hline Current type of practice: & $\begin{array}{l}\text { Academic medical center | Private practice urology- solo } \\
\text { | Private practice urology- group | Multispecialty group | } \\
\text { Federal }\end{array}$ \\
\hline Current AUA section: & $\begin{array}{l}\text { Northeastern | New England | New York | Mid-Atlantic | } \\
\text { Southeastern | North Central | Western | South Central | } \\
\text { Not sure | Not applicable (international) }\end{array}$ \\
\hline $\begin{array}{l}\text { Are you an international member of the Endourological } \\
\text { society working outside of the United States? }\end{array}$ & Yes | No \\
\hline Number of years in practice: & $\begin{array}{l}\text { In training | Less than } 1 \text { year } \mid 1 \text { to } 4 \text { years } \mid 5 \text { to } 10 \text { years } \\
11 \text { to } 20 \text { years | More than } 20 \text { years }\end{array}$ \\
\hline Fellowship completed: & Yes* $\mid$ No $(* 1$ following branching question) \\
\hline *Type of fellowship: & $\begin{array}{l}\text { Endourology/Stone Disease | Minimally Invasive } \\
\text { Surgery (i.e. laparoscopic/robotic) | Combined } \\
\text { Endourology and MIS | Other* }(* 1 \text { following branching } \\
\text { question) }\end{array}$ \\
\hline *Other fellowship: & [Text box] \\
\hline \multicolumn{2}{|c|}{$\begin{array}{l}\text { Section 2: The following questions refer to an index patient presenting with ureteral calculi } \leq 10 \mathrm{~mm} \text {, adequately } \\
\text { controlled pain, and without fever. }\end{array}$} \\
\hline What is your preferred initial approach? & $\begin{array}{l}\text { Observation | MET | URS | SWL | Stenting | NT } \\
\text { placement }\end{array}$ \\
\hline $\begin{array}{l}\text { What is the typical time interval from initial presentation in } \\
\text { ER to f/u in your clinic? }\end{array}$ & $<48$ hours | 48 hours-1 week | 1-2 weeks | >2 weeks \\
\hline $\begin{array}{l}\text { What percentage of patients with ureteral calculi are given } \\
\text { MET in your hospital ER? }\end{array}$ & $<25 \%|25-50 \%| 50-75 \%|>75 \%|$ Not sure \\
\hline $\begin{array}{l}\text { Do you currently prescribe/encourage medical expulsive } \\
\text { therapy (e.g. Flomax/Tamsulosin) to your patients with } \\
\text { ureteral calculi? }\end{array}$ & $\begin{array}{l}\text { Yes* | No | Not applicable }(* 4 \text { following branching } \\
\text { questions) }\end{array}$ \\
\hline $\begin{array}{l}\text { *For the index patient above, how often do you prescribe } \\
\text { medical expulsive therapy? }\end{array}$ & Never | Rarely | Sometimes | Often | Always \\
\hline $\begin{array}{l}\text { *Which stone locations would you utilize medical expulsive } \\
\text { therapy (choose all that apply) }\end{array}$ & Proximal ureter | Mid ureter | Distal ureter \\
\hline $\begin{array}{l}\text { *Which stone size(s) would you utilize MET (choose all that } \\
\text { apply) }\end{array}$ & $<5 \mathrm{~mm}|5-8 \mathrm{~mm}| 8-10 \mathrm{~mm} \mid>10 \mathrm{~mm}$ \\
\hline
\end{tabular}


Fedrigon et al

\section{Use of medical expulsive therapy}

\begin{tabular}{|l|l|}
\hline $\begin{array}{l}\text { *For the index patient above, how long would your MET } \\
\text { prescription be for? }\end{array}$ & [Text box] “Number of days in prescription” \\
\hline $\begin{array}{l}\text { Would you prescribe medical expulsive therapy to pregnant } \\
\text { patients with ureteral calculi? }\end{array}$ & Yes | No | Unsure/would defer to obstetrician \\
\hline $\begin{array}{l}\text { Would you prescribe medical expulsive therapy } \\
\text { postoperatively to patients who received shock wave } \\
\text { lithotripsy (SWL) treatment for ureteral calculi? }\end{array}$ & Yes | No \\
\hline $\begin{array}{l}\text { If you were the index patient above, what would be your } \\
\text { preferred treatment choice? }\end{array}$ & MET | URS | SWL | Stenting | NT placement \\
\hline Section 3: Recent trials of medical expulsive therapy \\
\hline $\begin{array}{l}\text { Are you aware of the controversy surrounding medical } \\
\text { expulsive therapy based on the recent paper (SUSPEND } \\
\text { trial) published the lancet in July of 2015 by McClinton et } \\
\text { al? }\end{array}$ & Yes* | No (*1 following branching question) \\
\hline *Did this controversy alter your use of MET? & Yes | No \\
\hline $\begin{array}{l}\text { Are you aware of the current AUA guidelines on the surgical } \\
\text { management of stones? }\end{array}$ & Yes | No \\
\hline Is more research on MET warranted? & Yes | No \\
\hline Is more education of ER personnel on MET necessary? & Yes | No \\
\hline
\end{tabular}




\begin{tabular}{|c|c|c|c|c|c|c|}
\hline \multicolumn{7}{|c|}{ Supplementary Table 2. Full demographic data } \\
\hline & $\begin{array}{c}\text { US } \\
(n=84)\end{array}$ & $\begin{array}{c}\text { International } \\
(\mathbf{n}=\mathbf{1 5 3})\end{array}$ & $\begin{array}{c}\text { Academic } \\
(\mathrm{n}=144)\end{array}$ & $\begin{array}{c}<10 \text { years in } \\
\text { practice } \\
(n=81)\end{array}$ & $\begin{array}{c}\text { Endo fellow } \\
(n=154)\end{array}$ & $\begin{array}{c}\text { Total } \\
(\mathbf{n}=237)\end{array}$ \\
\hline \multicolumn{7}{|l|}{ Type of practice (n) } \\
\hline Academic & $61 \%(51)$ & $61 \%(93)$ & - & $64 \%(52)$ & $69 \%(106)$ & $61 \%(144)$ \\
\hline Private, solo & $7 \%(6)$ & $11 \%(16)$ & - & $7 \%(6)$ & $6 \%(9)$ & $9 \%(22)$ \\
\hline Private, group & $20 \%(17)$ & $14 \%(22)$ & - & $11 \%(9)$ & $14 \%(21)$ & $16 \%(39)$ \\
\hline Multispecialty group & $8 \%(7)$ & $7 \%(11)$ & - & $7 \%(6)$ & $6 \%(9)$ & $8 \%(18)$ \\
\hline Federal & $4 \%(3)$ & $7 \%(11)$ & - & $10 \%(8)$ & $6 \%(9)$ & $6 \%(14)$ \\
\hline \multicolumn{7}{|l|}{ Years in practice (n) } \\
\hline In training & $0 \%(0)$ & $1 \%(2)$ & $1 \%(2)$ & - & $1 \%(1)$ & $1 \%(2)$ \\
\hline$<1$ year & $2 \%(2)$ & $0 \%(0)$ & $1 \%(1)$ & - & $1 \%(1)$ & $1 \%(2)$ \\
\hline $1-4$ years & $12 \%(10)$ & $12 \%(18)$ & $14 \%(20)$ & - & $14 \%(21)$ & $12 \%(28)$ \\
\hline 5-10 years & $25 \%(21)$ & $18 \%(28)$ & $20 \%(29)$ & - & $23 \%(35)$ & $21 \%(49)$ \\
\hline 11-20 years & $37 \%(31)$ & $30 \%(46)$ & $35 \%(51)$ & - & $37 \%(57)$ & $32 \%(77)$ \\
\hline$>20$ years & $24 \%(20)$ & $39 \%(59)$ & $29 \%(41)$ & - & $25 \%(39)$ & $33 \%(79)$ \\
\hline \multicolumn{7}{|l|}{ Fellowship-trained (n) } \\
\hline Yes & $79 \%(66)$ & $67 \%(102)$ & $21 \%(30)$ & $25 \%(20)$ & - & $71 \%(168)$ \\
\hline No & $21 \%(18)$ & $33 \%(51)$ & $79 \%(114)$ & $75 \%(61)$ & - & $29 \%(69)$ \\
\hline \multicolumn{7}{|l|}{ Fellowship type (n) } \\
\hline $\begin{array}{l}\text { Endourology/stone } \\
\text { disease }\end{array}$ & $21 \%(14)$ & $52 \%(52)$ & $40 \%(45)$ & $25 \%(15)$ & - & $39 \%(66)$ \\
\hline $\begin{array}{l}\text { Minimally invasive } \\
\text { surgery (MIS) }\end{array}$ & $12 \%(8)$ & $8 \%(8)$ & $7 \%(8)$ & $13 \%(8)$ & - & $10 \%(16)$ \\
\hline $\begin{array}{l}\text { Combined endourology } \\
\text { and MIS }\end{array}$ & $59 \%(39)$ & 33\% (33) & $47 \%(53)$ & $58 \%(35)$ & - & $43 \%(72)$ \\
\hline Other & $8 \%(5)$ & $7 \%(7)$ & $6 \%(7)$ & $3 \%(2)$ & - & $8 \%(14)$ \\
\hline
\end{tabular}

